\title{
NEW FLAWS FOR QUALIFICATION OF CAST STAINLESS STEEL INSPECTION
}

\author{
Iikka Virkkunen, Trueflaw Ltd., Finland, \\ Doug Kull, EPRI NDE-Center, USA, \\ Mika Kemppainen, Trueflaw Ltd., Finland
}

\begin{abstract}
For decades, cast austenitic stainless steels (CASS) have presented a challenge for inspection. However, recent advanced inspection technologies have shown promise in inspecting CASS materials with wall thicknesses that were once considered impossible.

Before being applied on a large scale, these new inspection methods must be proven to be effective at identifying discontinuities in CASS material. This presents a problem of its own. Several traditional flaw manufacturing methods cannot be applied to CASS due to the disruption of the parent material. Excavation and welding changes the cast material microstructure and can significantly affect the inspection results. At the same time, due to the significant wall thickness and inspection limitations, the required qualification flaws can be quite large. Until recently, modern flaw manufacturing techniques, that do not require welding, have not been applied to flaws of this size.

In this paper, recent developments will be presented on the manufacturing of thermal fatigue cracks in centrifugally CASS material. The presented developments make it possible to use real cracks for demonstrating the effectiveness of CASS inspection techniques.
\end{abstract}

\section{INTRODUCTION}

Cast austenitic stainless steel (CASS) materials are used extensively in reactor coolant pressure boundary components including pipes, fittings, valve bodies and pump castings in pressurized-water reactors (PWRs) throughout the world. The main coolant line and branch lines of many plant types contain cast components. In Table 1, a summary of main coolant line and branch line materials is shown for those plant types that include cast stainless steels. For many manufacturers, both wrought austenitic stainless steel (WASS) and CASS has been used. For Framatome plants, the use of CASS is concentrated on the elbows, and there's and some plants have elected to replace these cast elbows over time [1]. The surge lines are generally fabricated from WASS except in some Combustion Engineering plants where they are fabricated from CASS.

Table 1. Main coolant line and branch line materials according to plant type [2]

\begin{tabular}{ccc}
\hline Plant type & Piping & Elbows \\
\hline Westinghouse & WASS, CASS & CASS, bent pipe \\
Framatome & WASS, CASS & CASS, bent pipe \\
B\&W & WASS & CASS, bent pipe \\
Combustion & WASS, CASS (CF-8M) & CASS (CF-8M) \\
\hline
\end{tabular}

The use of CASS materials for these components is motivated by the favorable corrosion resistance properties as well as the relatively low cost. The service record of CASS components has also been good thus far.

It has been shown that CASS material exposed to high temperatures for prolonged periods of time can be susceptible to thermal aging. Thermal aging causes the decrease in material ductility and critical flaw sizes. For inspection, this has the effect of decreasing the size of the inspection target. The reduction in fracture toughness decreases the critical flaw size and thus the allowable flaw size for these components. E.g., Cicero et al. (2009) calculated critical flaw sizes in the range of 10 - $20 \mathrm{~mm}$ (0.4 - 0.8"; $40-80 \%$ through-wall ) for aged valve component with remaining Charpy impact energy of $65 \mathrm{~J} / \mathrm{cm}^{2}$. 
Cast stainless steel components are used in safety-related systems and there is evidence that shows that CASS materials can be susceptible to thermal fatigue under certain conditions [5]. Consequently, there has been an increased interest in developing a reliable in-service inspection method for CASS material. The non-destructive evaluation of cast stainless steel components has proven quite challenging. The large and irregular grain size of some CASS materials greatly affects the propagation of ultrasonic waves causing attenuation, beam deflection and scattering. During the PISC-III study, the then-current state of the art inspection methods were evaluated against cast stainless steel samples and concluded that the detection performance, in general, was satisfactory, whereas the performance for depth sizing was very poor. [6]

The poor performance observed lead to significant development efforts to facilitate the inspection of these important CASS components. In particular, synthetic aperture focusing (SAFT) techniques were utilized to decrease the noise level in the material by several authors [7,8,9]. In parallel, the use of eddy current (EC) techniques were studied [4], although the ID access required by the EC inspection would clearly impose problems for several locations. More recently, phased array ultrasonic techniques have been studied for inspection of cast stainless steel components $[8,10]$.

In summary, it's generally believed that current phased-array ultrasonic systems hold the best potential for the reliable inspection of cast stainless steel components. However, before the systems are applied on a larger scale, these new inspection methods must be proven to be effective at identifying and characterizing discontinuities in CASS material. To be able to demonstrate NDE reliability, test blocks representative of what is currently installed in the nuclear fleet are needed. Since the main feature making the inspection so challenging is the material microstructure, it's important that the samples contain representative microstructures. Also, the flaws to be used should be representative of postulated in-service induced flaws.

The complex grain structure and postulated fatigue damage mechanism eliminates several traditional flaw manufacturing methods in cast stainless steels base material. Because fatigue flaw faces are rough and tortuous, the EDM notches used in the PISC studies are not considered ideal for evaluating NDE techniques in CASS material. Also, the weld implanted flaws traditionally applied are problematic in components without joints due to the excavation required to introduce the simulated flaw. It is typically possible to detect the cavity and weld metal in the middle of the base material more easily than the actual flaw. Cracks have also been manufactured by mechanical loads. However, this is limited to simple shapes and, due to the heavy wall thickness, requires rather heavy loading equipment.

More recently, flaw manufacturing techniques based on controlled thermal fatigue have become available. This technique overcomes many of the deficiencies in the more traditional flaw manufacturing techniques. The material microstructure is not disturbed, since there's no welding involved in the process. Also, the thermal loads can be applied to heavy sections or complex shapes like elbows or pump casings. However, due to the significant wall thickness and inspection limitations, the required flaws for CASS can be quite large. Until recently, Trueflaw flaw manufacturing techniques have not been applied to flaws deeper than $15 \mathrm{~mm}$. In this paper, recent developments will be presented on the manufacturing of thermal fatigue cracks in CASS material. The work was performed by EPRI and Trueflaw and is still on-going.

\section{MATERIALS AND METHODS}

To develop test blocks for cast austenitic stainless steels, three samples were provided by EPRI. The samples were centrifugally cast CF-8M grade stainless steel with a varied equiaxed grain structure. Figure 1 shows a section of the material, used for this study, which has been polished and etched to show the grain structure. Two of the samples were used for actual test blocks whereas the third was reserved for development. Figures 2 and 3 show the sample geometry of the components as well as the flaw locations. 


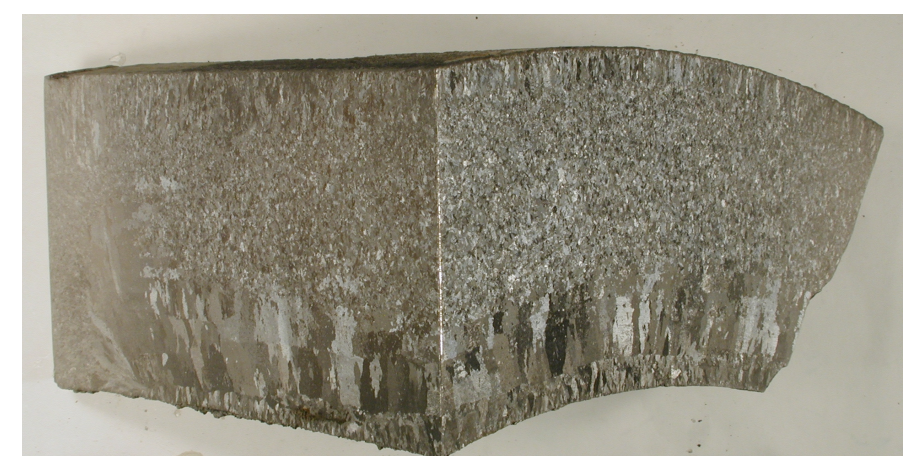

Figure 1. Example of the samples grain structure
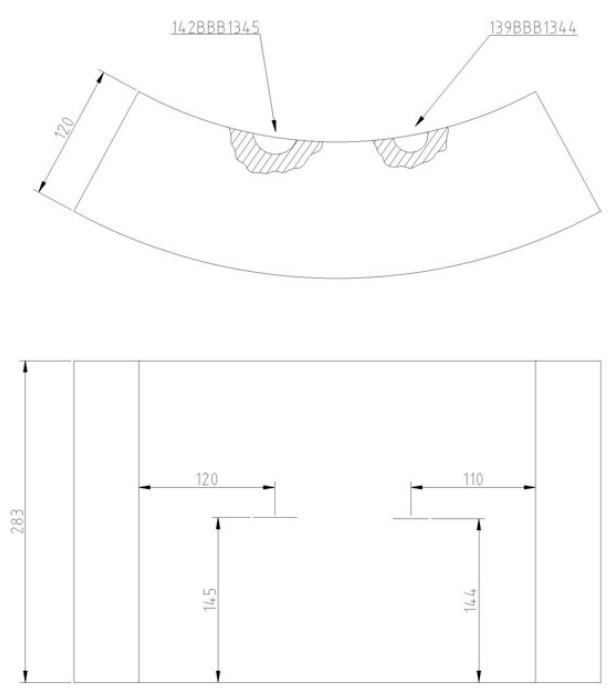

Figure 2. Sample geometry and flaw locations for cracks with $15 \mathrm{~mm}$ target depth 

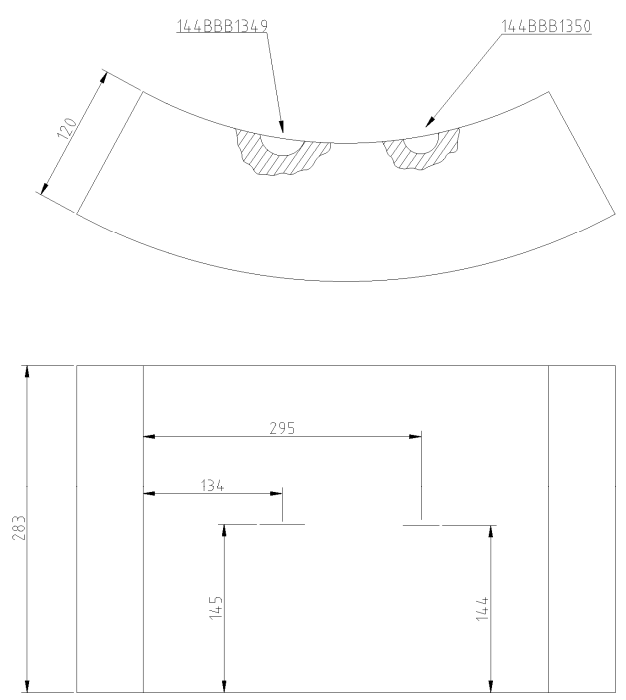

Figure 3. Sample geometry and flaw locations for cracks with $30 \mathrm{~mm}$ target depth

In each test block, two flaws were produced by in-situ controlled thermal fatigue. Controlled thermal fatigue flaws have been available since early 2000's from Trueflaw. In recent years the technology has matured, tried and tested. Capability of the technique to produce realistic, representative flaws has been analyzed by comparing the crack characteristics to the characteristics measured from service-induced flaws. This comparison has been made against measured values from service-induced flaws reported by Wåle [11]. The comparison indicated the flaws produced by the new technique are representative of several types of service-induced flaws.

To ensure reliable crack production and to know the depth of the produced cracks, each different crack produced is first validated destructively. That is, a crack is grown with a predetermined set of parameters and destructively examined to reveal the depth. Then, the same process can be repeated any number of times to produce number of similar cracks with known depth. This process is followed for each material and flaw size.

Thermal fatigue loading is characteristically greatest at the surface and decays with distance from the surface. Consequently, crack production is fastest near the surface and gets slower with increasing crack depth. The significant challenge for this project was that the cracks needed to be much deeper than previously manufactured.

The first sample contained two cracks with target depth of $15 \mathrm{~mm}(0.59 ")$. One of these cracks will remain intact while the other will be used as a validation crack, and will be destructively examined at later time. Sample 2 was designed to have two cracks, with one serving as validation crack for the other after destructive examination. The target depth for the second set cracks was $30 \mathrm{~mm}(1.18 ")$. A significant amount of development was necessary, because flaws of this depth had previously never been produced with Trueflaws techniques. During the development, numerous production tests were done and destructively examined. This included a number of partial validations, where crack growth rates from several depths were tested in samples with EDM-notch starter of known depth.

After the four cracks were grown in the two samples, the cracks were documented, photographed and surface features measured. Both samples were sent to EPRI for non-destructive evaluation. After thorough evaluation, the validation cracks will be destructively examined to confirm the true crack depths. 


\section{RESULTS}

Figure 4 shows fracture surface image from a preliminary thermal fatigue flaw production test completed. The fracture surfaces show features typical for fatigue cracking. The fracture surface is markedly uneven.showing the effect of the coarse microstructure. Although the overall shape of the crack is semielliptic, the crack tip also shows waviness, which indicates that the local microstructural features cause crack acceleration and retardation. Figures 5 through 8 show penetrant images from the cracks produced for this study. It is suspected that the large grain structure caused significant tortuosity to all cracks. Figures 9 and 10 show the crack surface roughness measured from the surface. Typical $R_{a}$ values for similar cracks in wrought stainless steels range from 15 to $65 \mu \mathrm{m}$. Some level of secondary cracking was present in all cases but was most significant in conjunction with the deeper cracks.

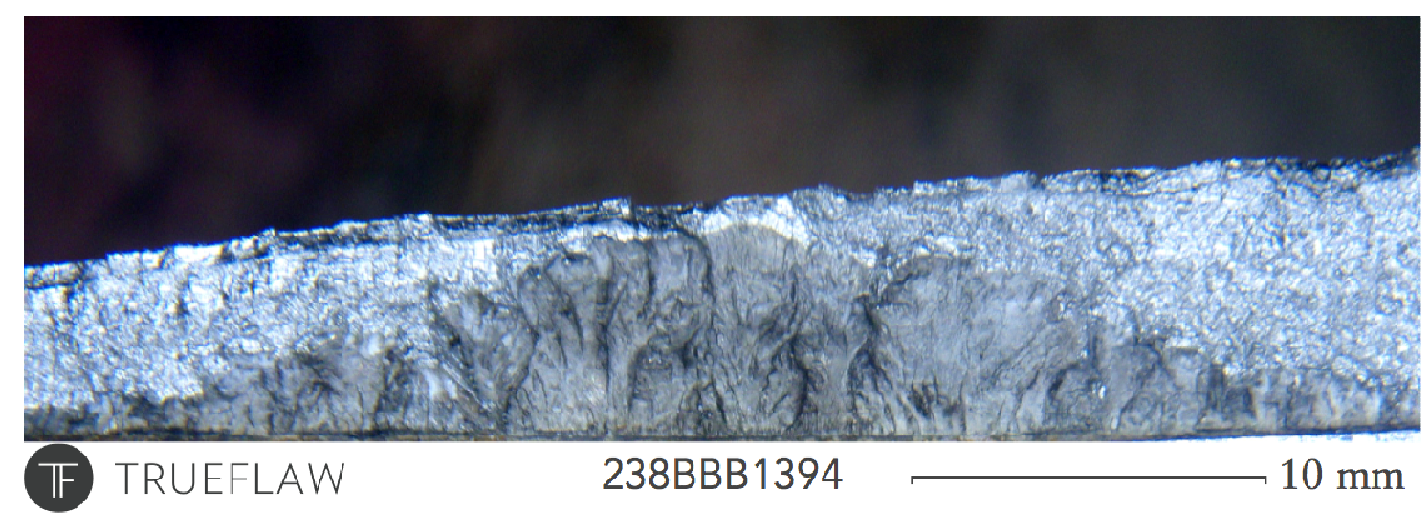

Figure 4. Fracture surface image from a production trial. The crack fracture surface is seen as darker area at the lower part of the image. The strong influence of coarse microstructure is evident from the fracture surface.

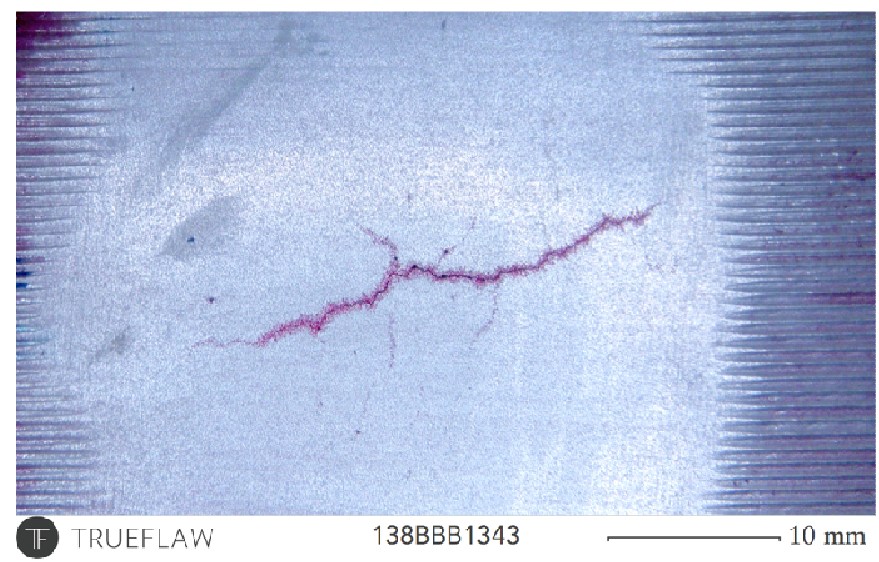

Figure 5. Red dye penetrant image of a produced crack (15 $\mathrm{mm}$ target depth). 


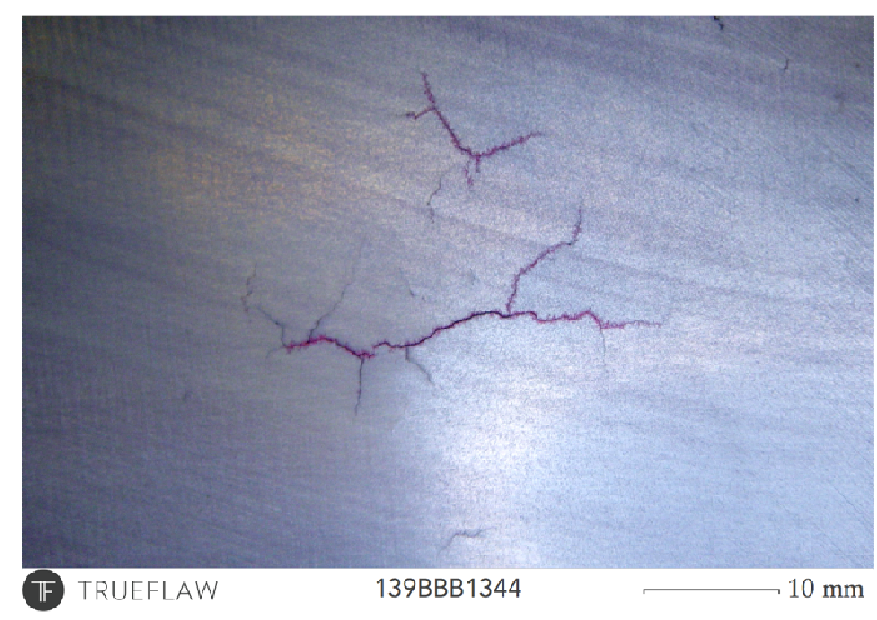

Figure 6. Penetrant image of produced crack (15 mm target depth).

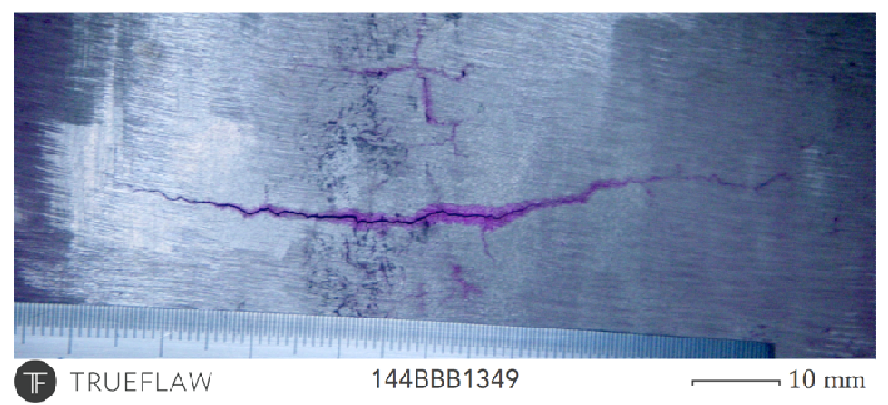

Figure 7. Penetrant images of produced crack (30 mm target depth).

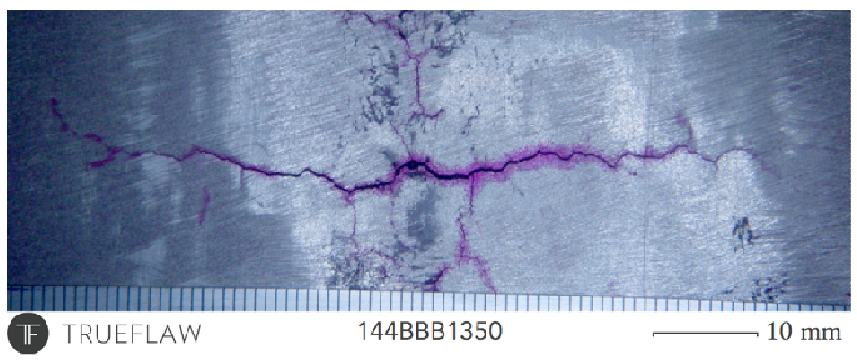

Figure 8 . Penetrant images of produced crack (30 $\mathrm{mm}$ target depth). 


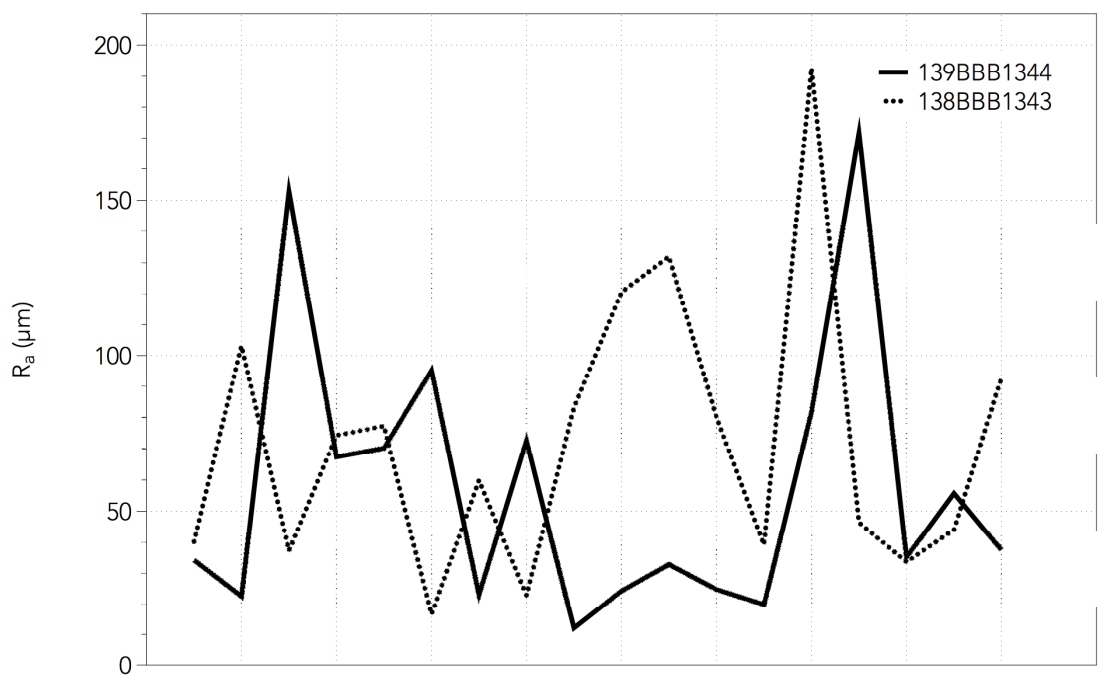

Figure 9. Crack roughness $\left(\mathrm{R}_{\mathrm{a}}\right)$ measured from surface (15 $\mathrm{mm}$ target depth).

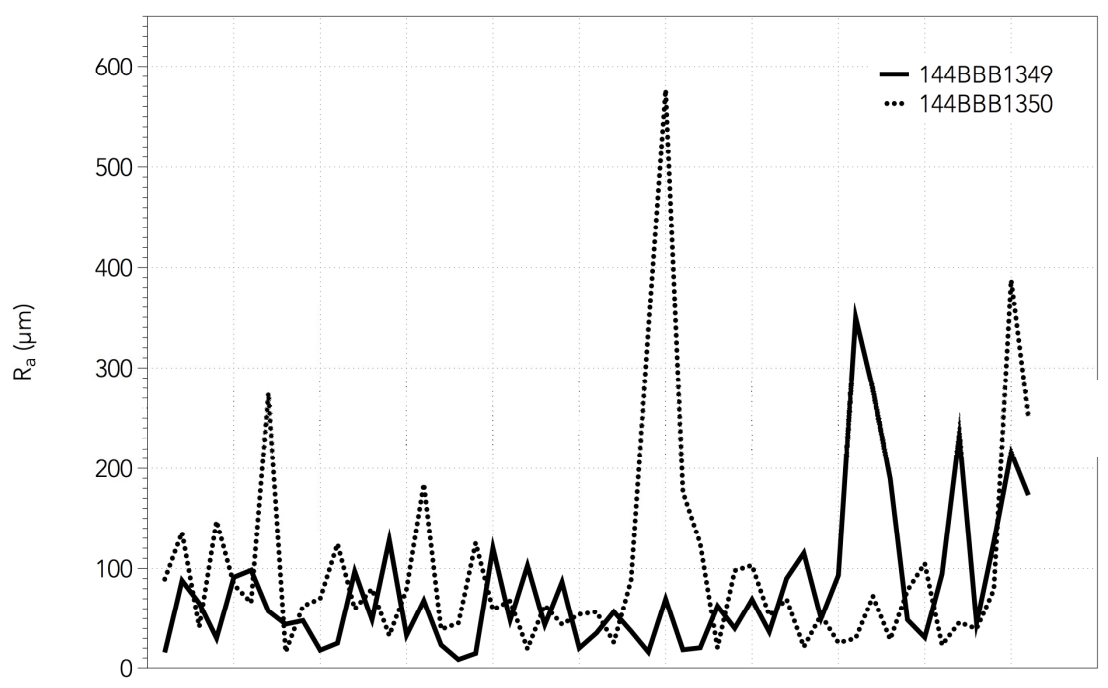

Figure 10. Crack roughness $\left(\mathrm{R}_{\mathrm{a}}\right)$ measured from surface (30 $\mathrm{mm}$ target depth).

Preliminary results from the NDE evaluation indicate that the cracks in Samples 1 and 2 are readily detectable with techniques utilizing low frequency ultrasonic transducers. Currently, data has been collected using phased array search units ranging in frequencies between $500 \mathrm{kHz}$ and $1.5 \mathrm{MHz}$. It has been noted that the data collected with lower refracted angles and lower frequencies experience less affects from the varying grain structure. Figures 11 through 18 show the signal characteristics of the flaws using search units with different frequencies. In some cases, the beam redirection has been noticeably different when scanning with the same search unit in opposite directions. The extraneous cracking around the intentional flaws has also been identifiable using the UT techniques and in some cases it is believed to partially mask the response from the primary target. Work is currently underway to subject samples to additional NDE testing. . 


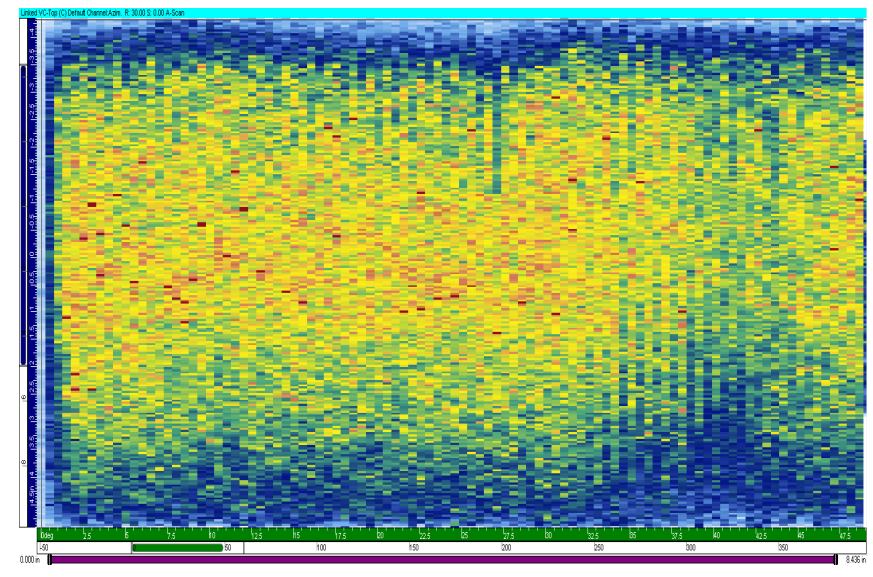

Figure 11 - Sample 1 using $1.5 \mathrm{MHz}$ search unit (C-scan)

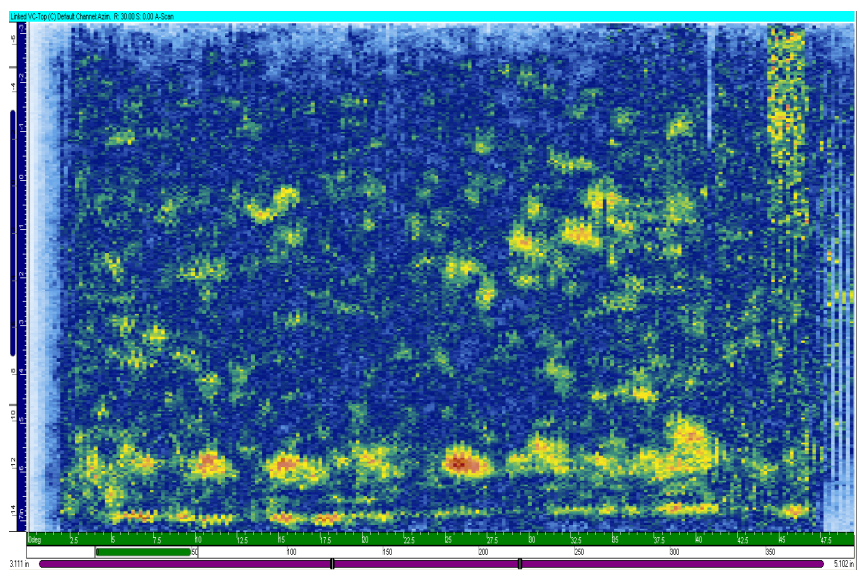

Figure 12 - Sample 1 using 1.00 MHz search unit (C-scan)

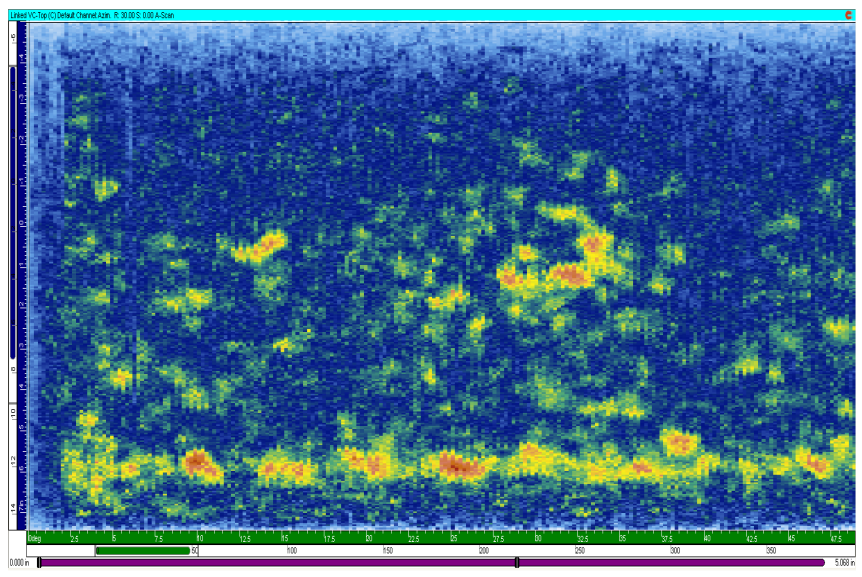

Figure 13 - Sample 1 using $0.75 \mathrm{MHz}$ search unit (C-scan) 


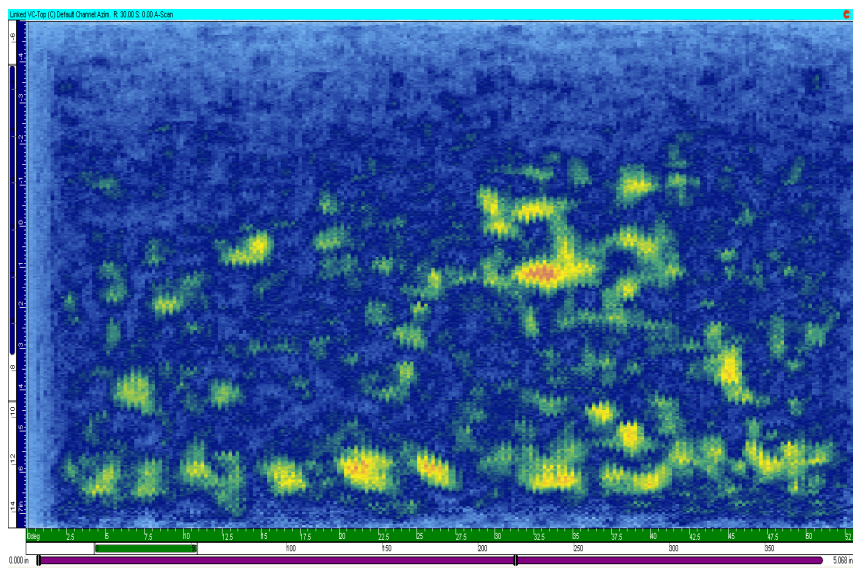

Figure 14 - Sample 1 using 0.50 MHz search unit (C-scan)

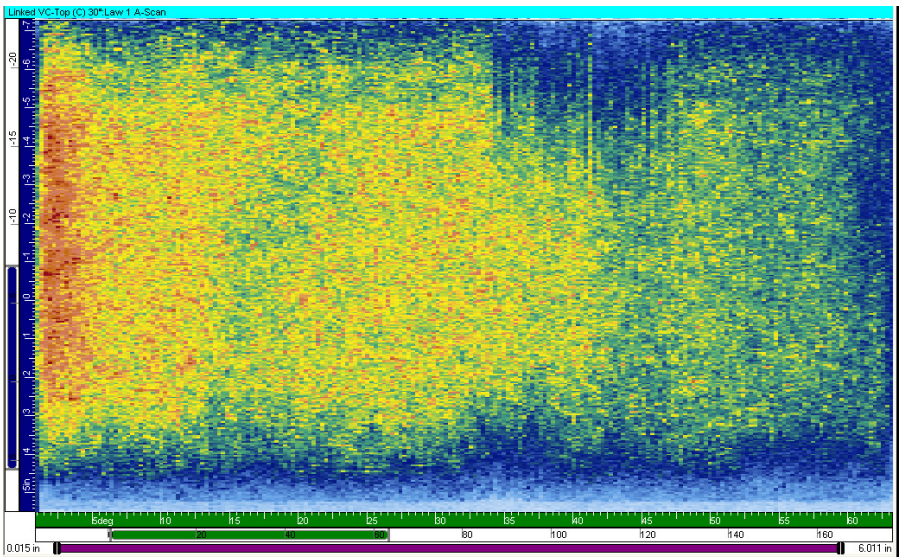

Figure 15 - Sample 2 using 1.0 MHz search unit (C-scan)

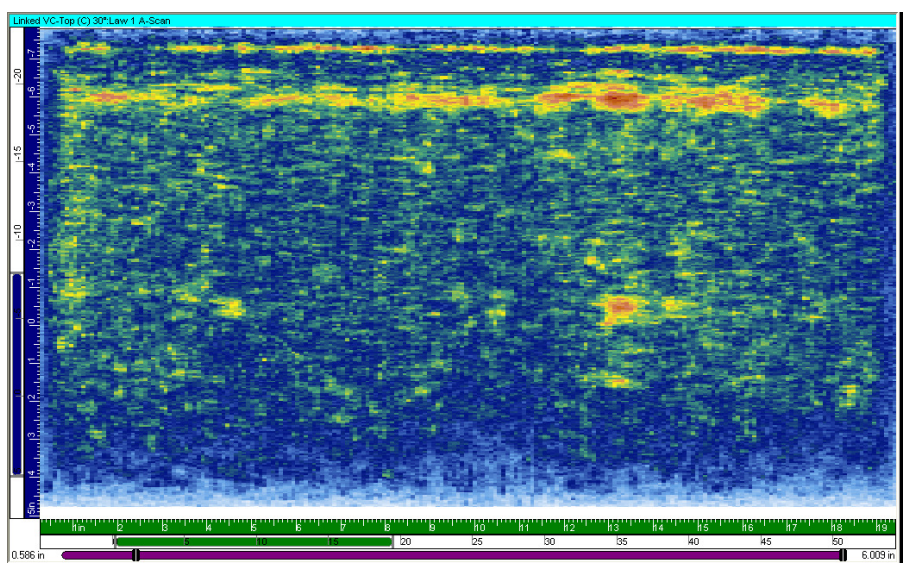

Figure 16 - Sample 2 using 1.0 MHz search unit (C-scan) 


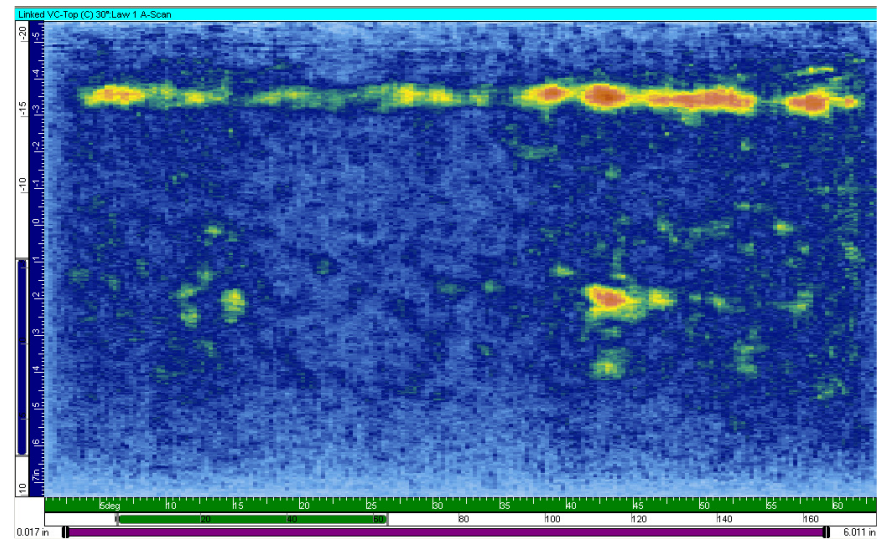

Figure 17- Sample 2 using $0.75 \mathrm{MHz}$ search unit (C-scan)

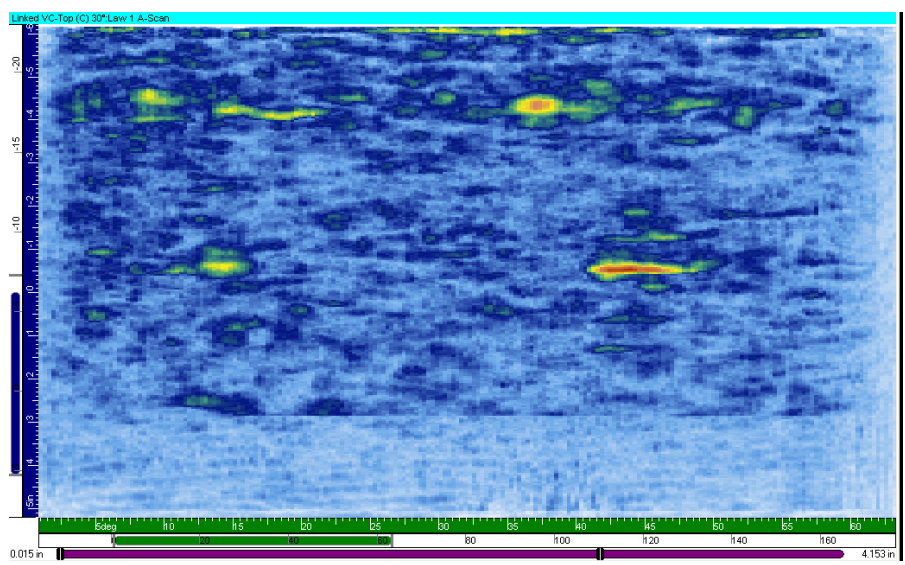

Figure 18 Sample 2 using $0.50 \mathrm{MHz}$ search unit (C-scan)

\section{DISCUSSION}

In view of the production tests and partial validations, the development of crack growth into cast stainless steel was a success. The final depth will be revealed, after the destructive examination is complete. Further development is needed to eliminate the secondary cracking experienced with the deeper flaws. Secondary cracks could be avoided in the production tests and partial validations, and thus can be overcome with some additional development.

The crack characteristics measured from the sample surface indicate that cracks produced in the cast material exhibit greater crack path tortuosity, which is reflected in the greater $R_{a}$ values measured from the surface. The measured $R_{a}$ values range from 50 to $300 \mu \mathrm{m}$ and more whereas the typical $R_{a}$ values for similar cracks in WASS are in the range of $15 \ldots 65 \mu \mathrm{m}$. This increase in $\mathrm{R}_{\mathrm{a}}$ is readily explained by the large grain structure of the material. The growing cracks find the weakest path through the microstructure and thus the grain size markedly affects the crack path tortuosity.

The ultrasonic data images above show the C-scan images for a $30^{\circ}$ angle with four different search unit frequencies. It can be seen that the noise level increases as the search unit frequency is increased up to $1.5 \mathrm{MHz}$. The noise levels decrease because increased wavelengths of the pulsed energy from a low frequency search units interact less with the individual grain boundaries of course grained material. In this case the $30^{\circ} 0.75 \mathrm{MHz}$ search unit best images the two flaws in Sample 1. The higher frequency search units have too much noise and the lowest frequency search unit does not seem to have enough resolution 
to image the first flaw.

Additional NDE work is scheduled for this study throughout 2012. Once all of the data is collected on the two specimens, at full thickness, the samples OD will be machined to reduce the thickness by $25 \%$. Ultrasonic data, matching that which has already been collected, will be acquired and compared before taking additional material off of the OD surface. By reducing the wall thickness of the mockup the crack through-wall percentage will increase. After several iterations of taking data and removing additional material it is hoped that conclusions can be made on the effects of CASS material thickness and the inspectability. Once the sample thickness has been reduced enough that the cracks represent 80 to $90 \%$ through wall the validation cracks will be destructively analyzed to determine the true depth.

\section{CONCLUSIONS}

In view of the production tests and partial validations, the development of crack growth into cast stainless steel was a success. The final depth will be revealed, after the destructive examination is complete and final judgment will then be available. Also, further analysis of the crack characteristics is made possible by the destructive examination.

With the increased NDE technology now available it seems that meaningful inspections of CASS components has increased, but additional work is needed to quantify its true capability. It is important to have realistic mockups to evaluate new NDE techniques and controlled thermal fatigue flaws have shown promise for this purpose. Additional work is required to develop methods of creating deeper flaws and determine if the individual grain structure of the base material has any effect on the crack growth.

\section{REFERENCES}

1) Chockie, A. "Summary Report. 3rd International Workshop on the Future Directions for the Inspection of Cast Austenitic Stainless Steel Piping". January 28 - 29, 2011 Seattle, WA. 2011.

2) IAEA. "Assessment and management of ageing of major nuclear power plant components important to safety - Primary piping in PWRs". IAEA-TECDOC-1361, International atomic energy agency, Vienna. ISBN 92-0-108003-4. 2003.

3) Lee, S, Kuo, P. T., Wichman, K. \& Chopra, O. "Flaw evaluation of thermally aged cast stainless steel in light-water reactor applications". International Journal of Pressure Vessels and Piping (72) pp. 37-44. 1997.

4) Cicero, S., Setién, J. \& Gorrochategui, I. "Assessment Of Thermal Aging Embrittlement In A Cast Stainless Steel Valve And Its Effect On The Structural Integrity". Nuclear engineering and Design (239) pp. 16 - 22. 2009.

5) Diaz, A.A., Mathews, R. A., Hixon, J. \& Doctor, S.R. "Assessment of Eddy Current Testing for the Detection of Cracks in Cast Stainless Steel Reactor Piping Components". United States Nuclear Regulatory Commission. NUREG/CR-6929. Available online: http://pbadupws.nrc.gov/docs/ML0706/ML070670477.pdf (referred 2012-02-08). 2007.

6) Lemaintre, P., Koblé, T. D. \& Doctor, S. R. "Summary of the PISC round robin test results on wrought and cast austenitic steel weldments, part III: cast-to-cast capability study". International Journal of Pressure Vessels and Piping (69) pp. 33-44. 1996.

7) Diaz, A. A., Harris, R.V. \& Doctor, S.R. "Field Evaluation of Low-Frequency SAFT-UT on Cast Stainless Steel and Dissimilar Metal Weld Components". United States Nuclear Regulatory Commission. NUREG/CR-6984. 104 p. Available online: http://pbadupws.nrc.gov/docs/ML0900/ML090020419.pdf (referred 2012-02-08). 2008.

8) Anderson, M. T., Crawford, S. L., Cumblidge, S. E., Denslow, K. M., Diaz, A. A. \& Doctor, S. R. "Heavy-Walled Cast Stainless Steel Piping Welds Using Advanced Low-Frequency Ultrasonic Methods". United States Nuclear Regulatory Commission. NUREG/CR-6933. Available online: http://www.nrc.gov/reading-rm/doc-collections/nuregs/contract/cr6933/ (referred 2012-02-08). 2007. 
9) Spies, M. \& Rieder, H. "Synthetic Aperture Focusing of Ultrasonic Inspection Data to Enhance the Probability of Detection of Defects in Strongly Attenuating Materials". NDT\&E International (43) pp. 425-431. 2010.

10) Mahaut, S., Godefroit, J.-L., Roy, O. \& Cattiaux, G. "Application of Phased Array Techniques to Coarse Grain Components Inspection". Ultrasonics (42) pp. 791-796. 2004.

11) Wåle, J. "Crack Characterisation for In-Service Inspection Planning - an Update". SKI reference 14.43-200543105, ISRN SKI-R-06/24-SE, SKI, Stockholm, Sweden. 2006. 